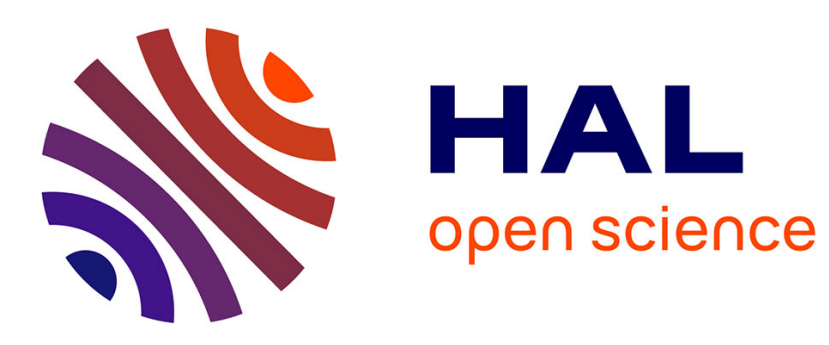

\title{
New Dependability Approach for Implanted Medical Devices
}

\author{
Fabien Soulier, Fanny Le Floch, Serge Bernard, Guy Cathébras
}

\section{To cite this version:}

Fabien Soulier, Fanny Le Floch, Serge Bernard, Guy Cathébras. New Dependability Approach for Implanted Medical Devices. International Conference on Microelectronics, Dec 2009, Marrakech, Morocco. hal-00413484

\section{HAL Id: hal-00413484 https://hal.science/hal-00413484}

Submitted on 4 Sep 2009

HAL is a multi-disciplinary open access archive for the deposit and dissemination of scientific research documents, whether they are published or not. The documents may come from teaching and research institutions in France or abroad, or from public or private research centers.
L'archive ouverte pluridisciplinaire HAL, est destinée au dépôt et à la diffusion de documents scientifiques de niveau recherche, publiés ou non, émanant des établissements d'enseignement et de recherche français ou étrangers, des laboratoires publics ou privés. 


\title{
New Dependability Approach for Implanted Medical Devices
}

\author{
Fabien Soulier*§, Fanny Le Floch*§, Serge Bernard ${ }^{\dagger \S}$ and Guy Cathébras*§ \\ *University Montpellier II \\ ${ }^{\dagger}$ French National Center for Scientific Research (CNRS) \\ $\S$ Montpellier Laboratory of Informatics, Robotics, and Microelectronics (LIRMM) \\ 161 rue Ada - 34392 Montpellier Cedex 5 - France \\ Email: \{Firstname.Lastname\}@lirmm.fr
}

\begin{abstract}
Functional Electrical Stimulation (FES) is an attractive solution to restore some lost or failing physiological functions. Obviously, the FES system may be hazardous for patient and the reliability and dependability of the system must be maximal. Unfortunately, the present context, where the associated systems are more and more complex and their development needs very cross-disciplinary experts, is not favorable to safety. Moreover, the direct adaptation of the existing dependability techniques from domains such as space or automotive is not suitable.

Firstly, this paper proposes a strategy for risk management at system level for FES medical implant. The idea is to give a uniform framework where all possible hazards are highlighted and associated consequences are minimized. Then, the paper focuses on one of the most critical part of the FES system: analog micro-circuit which generates the electrical signal to electrode. As this micro-circuit is the closest to the human tissue, any failure might involve very critical consequences for the patient. We propose a concurrent top-down and bottom-up approach where the critical elements are highlighted and an extended risk analysis is performed.
\end{abstract}

\section{INTRODUCTION}

Functional Electrical Stimulation (FES) is quite often used to restore damaged physiological functions. Because of the implantation of the system inside the human body, the reliability and safety of the implant have to be perfectly controlled. Unfortunately, the complexity of implant endlessly increases, as a result, providing the highest safety is a real challenge. As an illustration, until now, the classical cochlear implant was composed of an external part including a microphone, a speech processor and an RF transducer coupled with a coil implanted beneath the skull's skin and an internal circuit inside the cochlea stimulating auditory nerves with an electrical current. The system was rather basic and the dependability study was easily done. But with the increase of the complexity and versatility of the system, the dependability study [1]-[3] has to be taken more seriously.

The development of such an implant brings a very highly cross-disciplinary context where physicians, surgeons, microelectronics and mechanical specialists have to work together. They have to take into account the expectation of each other even if the communication between these different communities is not easy. For example, the surgeon needs to be educated on how to manipulate an implant, which is highly sensitive to electric discharge. The experience shows that

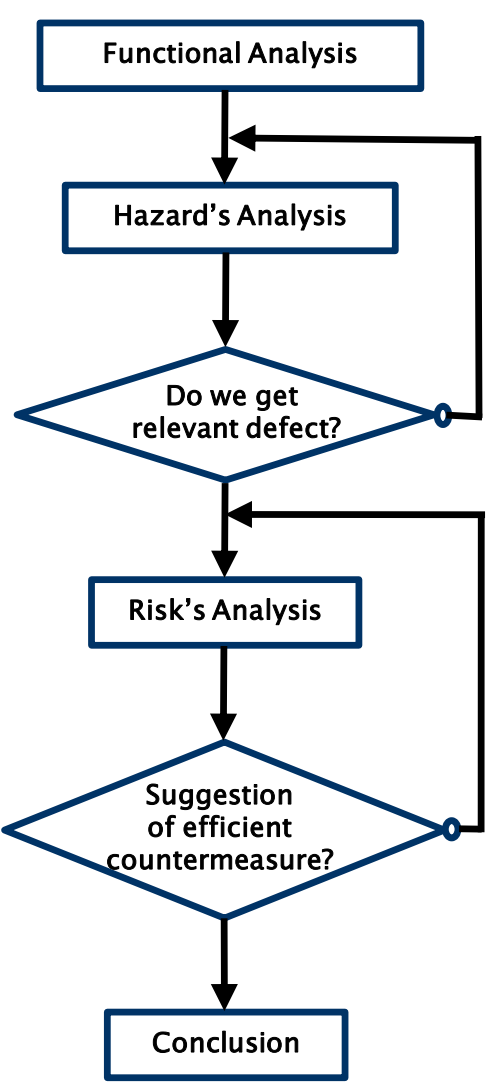

Fig. 1. Algorithm of the dependability system management.

sometimes working implant before the surgery was defective once they have been embedded inside the patient, due to a bad manipulation. The solution is then to test the implant before ending the surgery.

Firstly, this paper presents a new strategy for risk management at system level for FES medical implant. The aim is to propose a uniform framework to highlight each potential hazard and solution to control and prevent them. The existing techniques developed in aeronautic, space or even automotive fields are not totally appropriated for the medical domain. The 
third section focuses on the electronic part of the cochlear implant. Finally, the last section introduces an efficient concurrent top-down and bottom-up approach on the analog part of the circuit.

\section{STRATEGY FOR RISK MANAGEMENT AT SYSTEM LEVEL}

\section{A. Objectives}

The high-level dependability management [4] gives us a chance to consider every potential defective point. One of the main objectives is to give a set of tools and guide lines suitable for any expert or set of experts of the entire system. The base of the proposed risk management is an algorithm which described the successive steps. This algorithm must be as simple as possible to achieve the best coverage of defective cases and propose the highest level of confident and safety of the system.

\section{B. Algorithm for risk management}

As shown in figure 1, we have developed an iterative algorithm for the dependability management. First, the functional analysis defines the system, its environment and its external limits. It points up that not only the implant inside the human body has to be taken care, but also the patient itself, the surgeon, the practitioner, the patient's activities... It is useful to understand and determine the patient's way of life. What sport does he practice? (Shocks can damage the implant) Does he need specific settings if he works in a noisy surrounding?

This step is essential because if the definition of the expected system functionalities is not precise and the possible user cases and external constraints are not exhaustive, a potential hazard context might appeared because it was not taken into account. The other objective of this first step is to break up the system into functional blocks and general properties. Theses subsystems allow us to define working groups associated with specific expertise.

The second step is the hazard's analysis which draws up the full list of hazards that can occur. By means of a chart, we collect hazards into two separates categories: a specific and a generic part. The specific part corresponds with the functional decomposition of the project: the stimulation architecture, the wireless and power interface, the embedded software, the neuro-sensing interface, the micro-mechanics module and the battery. The generic part is the segmentation of the system into properties such as: chemical properties, mechanical, physiological (ex: biocompatibility of the cover material of the implant with the human tissue), with regards to the environment (ex: electromagnetic compatibility), the diagnosis, concerning the radiation protection, the informations given by the manufacturer, concerning the practitioner, the surgeon, the patient, the implantation, the implant-life inside the human body [5], the disposal procedures. Once the patient is dead, the implant is removed from the body for environmental reasons.

This preliminary version is written by the person in charge of the dependability study. Once it is established, it is then sent to the working team, separated in smaller teams depending on their skills. The hazard chart has to be as exhaustive as possible. Afterwards, a risk analysis will be done: the purpose is to estimate the dependability level before and after the countermeasure to check the efficiency of the taken modification. For instance, there is a level shifter (see figure 3) which controls the high voltage part of the circuit, thanks to a low voltage digital part. We found out that this was a sensitive part of the implant, so the countermeasure we are developing is a simple down shifter. If the comparison of its input and the output of the level shifter is different, a warning is sent to the logic control, and the implant switches in a fail-soft mode.

The dependability study has to carry on over the entire life of the project, thanks to the experience feedback, the study can be completed and improved. The link between the person in charge of the dependability study and the after sales services is essential to keep collecting information for the existing implant and the future generation of implant.

\section{RISK ANALYSIS OF THE ELECTRONIC PART OF THE IMPLANT}

In this section, we focus on one of the most critical part of the implant: the electronic part. The analog part of the microcircuit generates the electrical signal send to the electrodes. As this micro-circuit is the closest to the human tissue, any failure might involve very critical consequences for the patient. As an illustration, we apply our approach to the cochlear implant.

\section{A. Case study: the cochlear implant}

Cochlear implant is used for deafness. The fundamental principle is to convert sound recorded with a microphone to electrical stimulations inside the cochlea. In this section, we present an overview of the future generation of this kind of implant where, to make life easier for the patient, the entire system will be implanted into the human body. The device is composed of an external controller [6], which has to be used every two days to recharge the internal integrated circuit by means of wireless link, as shown on figure 2 . The major difficulty with the battery is to give to the patient the freedom to recharge the implant whenever he wants (as long as he does it at least once a week), instead of restraining him on a precise time.

The embedded part inside the body is divided into two subsystems: a digital and an analog module. The digital module manages the communication with the external controller. It also receives the sound picked up from a microphone implanted inside the cochlear. The sound is processed before being send to the logic control, which determines the shape, the amplitude and the duration of the stimulation current [7], [8].

The power is supplied by a battery, implanted beneath the collarbone. The analog module contains a digital to analog converter (DAC), which provides the stimulation current. The high voltage generator is necessary to reach the maximum 


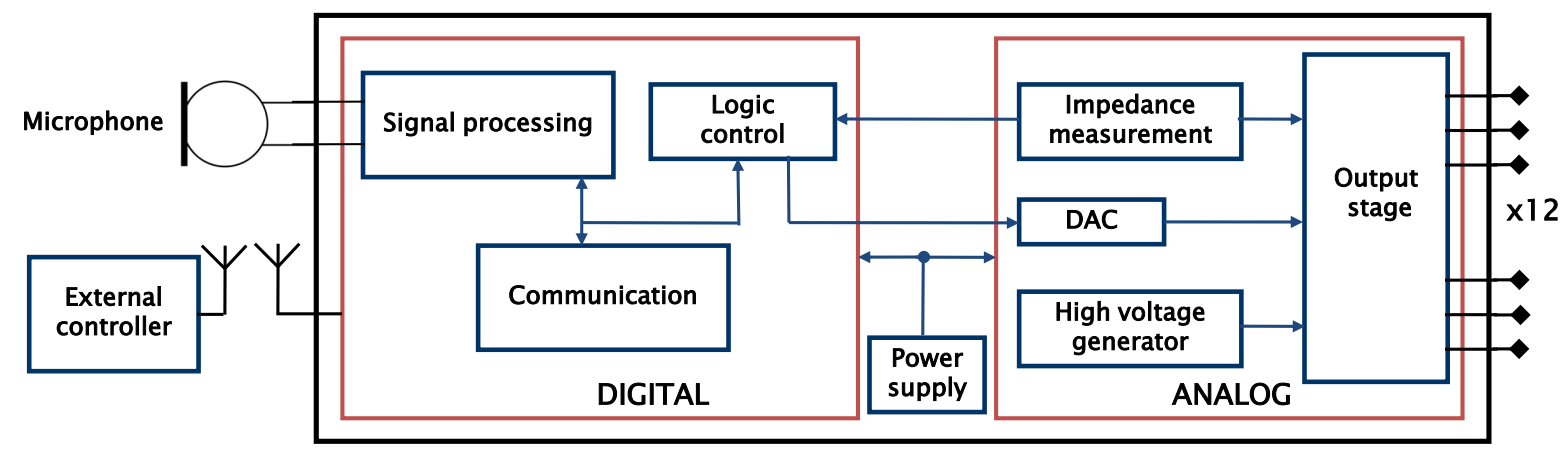

Fig. 2. Overview of the implant.

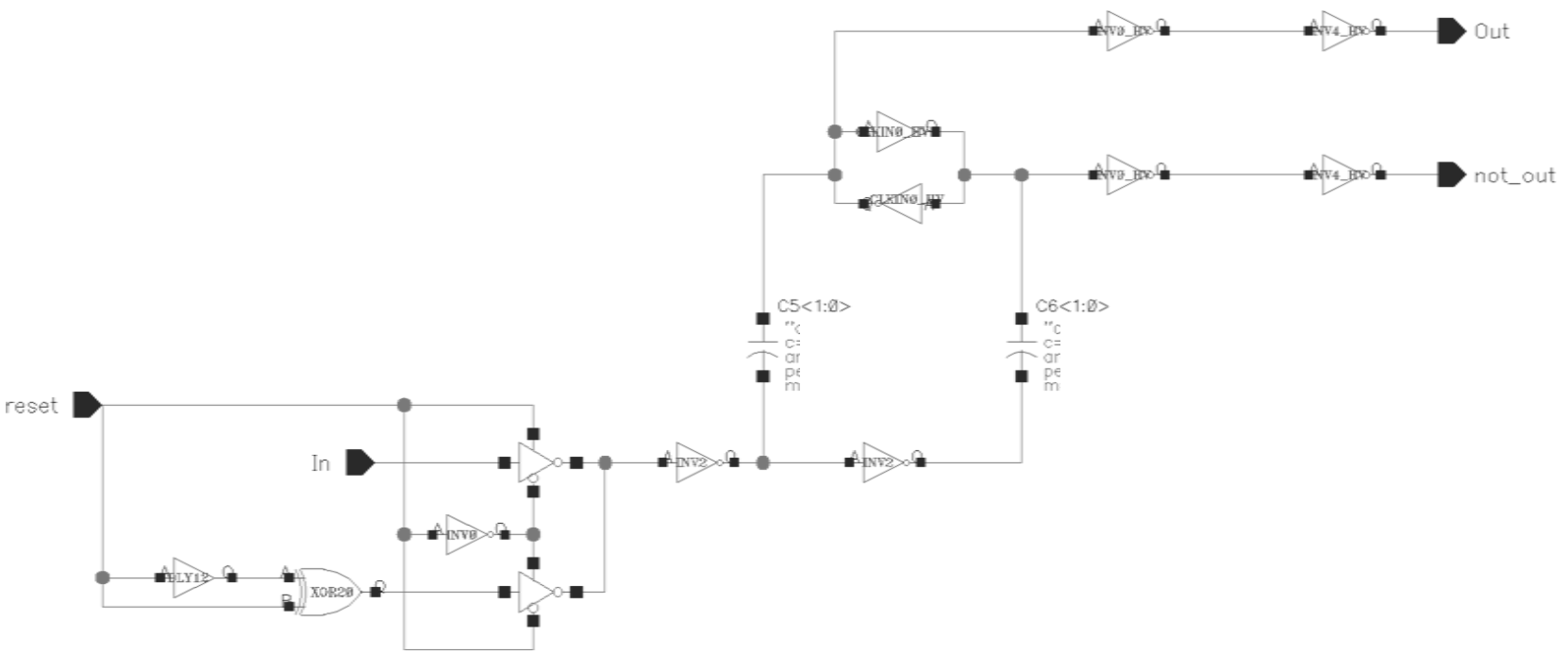

Fig. 3. Schematic of level shifter.

stimulation current needed. Finally, the output stage delivers the right current to the electrodes.

\section{B. The analog part of the FES implant}

Having a failure from the analog part of the micro-circuit can be a disaster because among other things, it is in direct contact with the human tissue. We use a approach based on concurrent top-down and bottom-up methods (see figure 4). The tangle of these two approaches brings out every potential failure and give us the exhaustive list of failures and allows us to develop specific Built-In-Self-Test and Built-In-Self-Repair solutions to enhance the safety during the life of the system.

1) The top-down approach:

The top-down approach consists of breaking down the system into finer details. We refine the system until we get to elementary structures.(The division stops when it seems irrelevant to go further). Each step of decomposition is analyzed in terms of failures, so the advantage is to consider every potential failure.
The study starts once the functional description has been done. The global view gives the opportunity to work not only on the embedded system inside the patient, but also, on every human which interact with the implant (the patient, the surgeon, the practitioner,...). The implant life is also examined: it begins with its manufacture, carriage, storage, implantation, life in the human body, and finally, its disposal procedures. Then, each specific expert team looks downer inside the global system. This approach helps us to cover the system from a macro overview to a micro decomposition.

\section{2) The bottom-up approach:}

The bottom-up approach starts with a basic element of the system, known as deficient and the following consequences of the deficiency are tracked up to the actual hazard. We can apply this method because the analog circuit is an improvement of an older version, so we can use the experience feedback. As an example, the impedance measurement helps to check if the electrodes are in open circuit, or short circuit, or even 


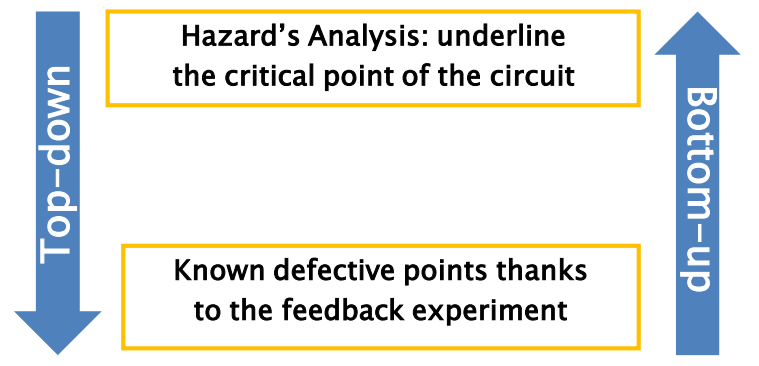

Fig. 4. Top-down and bottom-up method.
[5] Creasy, "Implications of implantation of bladder stimulation systems in children and adolescents," in Top spinal cord Inj rehabil. Thomas Land, 2000 .

[6] Cherukuri, Venkatasubramanian, and Gupta, "Biosec: A biometric based approach for securing communication in wireless networks of biosensors implanted in the human body," Proceedings of the 2003 International conference on parallel processing workshops, pp. 1530-2016, 2003.

[7] Guiraud, S. Koch, Divoux, and Rabischong, "An implantable neuroprosthesis for standing and walking in paraplegia: 5-year patient follow-up," Journal of Neural Engineering, vol. 3, pp. 268-275, 2006.

[8] D. Guiraud, T. Stieglitz, G. Taroni, and J.-L. Divoux, "Original electronic design to perform epimysial and neural stimulation in paraplegia," Journal of Neural Engineering, vol. 3, pp. 276-286, 2006.

damaged. This is a countermeasure that has been implemented in the latest version of the implant, we realized that if a short circuit occurred, we were not able to detect that the failure came from the electrode, we had to change not only the electrode, but the entire implant. Replacing a defective implant is not a minor operation. The patient has to go through another surgery and there is a delay to respect between the explantation of the defective implant and the implantation of the new one. Once every critical point has been listed, we can treat them by applying efficient countermeasure.

\section{CONCLUSION}

The complexity and versatility of implant leads to develop new methods proper to the medical field. One of the main tools for safety improvement is the algorithm of the risk management which gives a guideline to follow in order to obtain an exhaustive list of potential failures. Once this list is established, we can develop efficient Built-In-Self-Test and Built-In-Self-Repair solutions. The control of every critical element of the implant and its environment helps to increase the reliability and safety of the system. This approach is iterative, and needs to be updated during the entire life of the implant. In the next future, we will focus our research on the analog part of the circuit, which has been technically improved. Thanks to the experiment feedback on the old implant generations and the developed algorithm, this coming and going approach will provide a complete list of failures. Indeed, the top-down approach covers the system from a macro overview to a micro decomposition, whereas the bottom-up approach uses the experience feedback to repair know defects. This merge will bring us a highly safe and reliable medical implant to the patient advantage.

\section{REFERENCES}

[1] Halperin, Heydt-Benjamin, Fu, Kohno, and Maisel, "Security and privacy for implantable medical devices," IEEE Pervasive computing, vol. 7, pp. 30-39, mars 2008

[2] C. W. John B.bowles, "Software failure modes and effects analysis for a small embedded control system," IEEE Proceedings of the annual reliability and maintainability symposium, vol. 50, pp. 478-484, 2001.

[3] J. C. Knight, "Safety critical systems: challenges and directions," Software Engineering, vol. 1, pp. 547-550, 2002.

[4] A. Villemeur, sûreté de fonctionnement des systèmes industriels, Eyrolles, Ed., 1997. 